\title{
Embolia grasa macroscópica: el enemigo silencioso
}

\author{
Dr. Lázaro Cárdenas Camarena \\ Cirujano Plástico \\ INNOVARE Cirugía Plástica Especializada, Zapopan, Jalisco, México
}

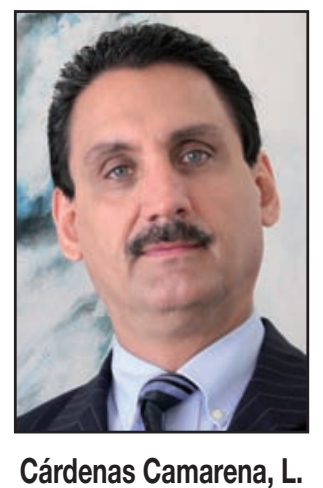

Es indudable que la transferencia de tejido graso autólogo se ha posicionado como un procedimiento multifuncional en nuestra especialidad. Las ventajas que proporciona en diversas áreas de la Cirugía Plástica eran antes impensables, y día a día surgen aplicaciones nuevas. Sin embargo, esta evolución y multifuncionalidad ha venido a ocasionar patologías que antes no existían o eran poco reportadas.

Tenemos la experiencia de haber estandarizado la lipoinyección glútea desde hace casi 20 años como un procedimiento de rutina en la mayoría de nuestras liposucciones (1); esto como consecuencia de haber egresado de una de las escuelas pioneras en este rubro, como es la del Dr. José Guerrerosantos. El Dr. Guerrerosantos y el Dr. Abel Chajchir nos introdujeron en este apasionante mundo de la transferencia de tejido graso autólogo; trabajaron intensamente con la infiltración grasa en la cara, y acerca en la supervivencia del tejido adiposo inyectado en el tejido muscular. Por nuestra parte, lo que hicimos fue trasportar todo ese mar de conocimientos y experiencias a otras áreas de la economía corporal. Así empezamos a inyectar grasa en glúteos en el plano intramuscular, con el objetivo principal de lograr una mayor supervivencia del tejido adiposo, obteniendo excelentes resultados estéticos $(1,2)$. Habíamos seguido esta conducta durante casi 10 años sin problema alguno, hasta que en el año 2001 acumulamos 2 casos de síndrome de embolismo graso que, afortunadamente, resolvimos de forma satisfactoria $(1,2)$.

A causa de estos 2 eventos nos surgió la siguiente pregunta ¿Tendría alguna implicación en la aparición de estos síndromes el hecho de infiltrar la grasa en el plano intramuscular? En estudios de investigación que realizamos encontramos que la inyección de grasa intramuscular, si bien es cierto que implica una mayor supervivencia del injerto, produce una mayor difusión de la grasa en la economía corporal. De igual forma, otros estudios nos demostraron que a mayor cantidad de grasa manipulada, mayor cantidad de grasa que entra al torrente circulatorio y se elimina por la orina. Nos quedó claro que la manipulación en exceso de la grasa y la infiltración in- tramuscular eran factores que podían favorecer la difusión a distancia de la grasa infiltrada. Revisando artículos científicos y casos de síndrome de embolismo graso, nos dimos cuenta de que la concentración de grasa en el torrente circulatorio es un factor desencadenante de los procesos bioquímicos y vasoactivos que llevan a la aparición de esta patología, por lo que también nos dimos cuenta de que la hidratación adecuada en estos casos es un factor protector muy importante que favorece la dilución de la grasa intravascular $(3,4)$. Afortunadamente, después de implementar una hidratación cuidadosa en todos los pacientes sometidos a manipulación de grasa, y pasar a infiltrar la misma en planos más superficiales para evitar su difusión, no hemos vuelto a tener un solo caso de síndrome de embolismo graso en 15 años, a pesar de que en la actualizad realizamos liposucciones y lipoinyecciones más extensas.

Parecía pues que el problema estaba resuelto en gran medida. Sin embargo, desde hace unos años a la fecha se empezaron a reportar un número importante de fallecimientos transoperatorios en pacientes sometidos a lipoinyección glútea. Estas muertes cursaban con un cuadro clínico totalmente diferente a lo que conocíamos acerca del síndrome de embolismo graso, ya que en este síndrome el problema aparece varios días después de la cirugía, y en los nuevos casos la muertes se producían durante la cirugía o a las pocas horas de haberla realizado, pero con un cuadro clínico que se iniciaba en el transoperatorio. Fue entonces cuando entendimos que nos estábamos enfrentando a una patología totalmente diferente y nos pusimos a la tarea de investigar qué estaba pasando.

Haciendo un estudio de investigación de casos y revisando fotografías de autopsias de los pacientes fallecidos, nos encontramos con la constante de que todos los pacientes con registros fotográficos tenían presencia de grasa macroscópica en grandes vasos y en cavidades cardíacas, encontrando también laceraciones de los vasos glúteos en la región piriforme con grasa en la luz de los vasos (5). Fue así como entendimos que los procedimientos de lipoinyección glútea en ocasiones laceraban o 
seccionaban la vena glútea, y a través de ella, la grasa era introducida en los grandes vasos y transportada a las cavidades cardiacas produciendo un embolismo graso macroscópico con resultados catastróficos fulminantes, tal y como se presentaba en los cuadros clínicos investigados, como patología totalmente diferente a la del síndrome de embolismo graso.

Hemos expuesto esta investigación en múltiples congresos y la hemos publicado científicamente con gran beneplácito, pero también hemos causado controversia porque es totalmente cierto que la aparición del cuadro no es común ni habitual. Fuimos de los primeros en iniciar las publicaciones sobre infiltración de grasa en glúteos hace más de 15 años (1). Somos de los autores que más publicaciones tenemos sobre contorno glúteo y lipoinyección glútea, con más de 1.500 casos en la actualidad de lipoinyección glútea, y afortunadamente nunca hemos tenido un caso de embolismo graso macroscópico. Consideramos que la ausencia de problemas se ha debido, en gran medida, a que a consecuencia de los 2 síndromes de embolismo graso que tuvimos hace 15 años cambiamos nuestra técnica de lipoinyección a planos más superficiales. Sin embargo, el que no hayamos tenido un solo caso de embolia grasa macroscópica no significa que la patología no exista; las muertes y las autopsias ahí están y lo demuestran sin duda alguna. Por lo tanto, debemos cambiar nuestra conducta a la hora de practicar la lipoinyección glútea y no esperar a que se nos presente un caso fatal por embolia grasa macroscópica para aceptar que el problema existe. Seguir las medidas precautorias habituales de usar cánulas romas, infiltrar en forma atraumática, con movimientos gentiles y con poca presión, es extremadamente útil; sin embargo, el punto clave es el no lesionar los vasos glúteos, por lo que debemos evitar la inyección intramuscular profunda cambiando nuestra técnica de infiltración a planos musculares más superficiales y a nivel subcutáneo. Es cierto que la supervivencia de la grasa se dará en menor porcentaje, pero después de un incidente catastrófico, ya nada es igual

\section{Bibliografía}

1. Cárdenas-Camarena L, Lacouture AM, Tobar-Losada A.: Combined gluteoplasty: liposuction and lipoinjection. Plast Reconstr Surg. 1999; 104 (5):1524-31; Discussion 1532-1533.

2. Cárdenas-Camarena L, Arenas-Quintana R, RoblesCervantes JA.: Buttocks fat grafting: 14 years of evolution and experience. Plast Reconstr Surg. 2011; 128(2): 545-555

3. Horne RH, Horne JH.: Fat embolization prophylaxis. Use of hypertonic glucose. Arch Intern Med. 1974; 133 (2):288-291.

4. McDermott ID, Culpan P, Clancy M, Dooley JF.: The role of rehydration in the prevention of fat embolism syndrome. Injury. 2002; 33 (9):757-759.

5. Cárdenas-Camarena L, Bayter JE, Aguirre-Serrano H, Cuenca-Pardo J.: Deaths Caused by Gluteal Lipoinjection: What Are We Doing Wrong? Plast Reconstr Surg. 2015;136 (1):58-66. 